\title{
Synthesis and Properties of 1,4-Bis(4-aminophenoxy)naphthalene and Its Polyimides
}

\author{
Chin-Ping $\mathrm{YANG}^{\dagger}$ and Jhy-An CHEN
}

Department of Chemical Engineering, Tatung Institute of Technology, 40 Chungshan North Rd., 3rd Sec., Taipei, Taiwan, Republic of China

(Received November 17, 1997)

\begin{abstract}
A new diamine 1,4-bis(4-aminophenoxy)naphthalene (1,4-BAPON) was prepared through the nucleophilic displacement of 1,4-dihydroxynaphthalene with $p$-fluoronitrobenzene in the presence of $\mathrm{K}_{2} \mathrm{CO}_{3}$ in $N, N$-dimethylacetamide (DMAc), followed by catalytic reduction with hydrazine and $\mathrm{Pd} / \mathrm{C}$ in ethanol. A series of novel aromatic polyimides containing 1,4-bis(aminophenoxy)naphthalene units was synthesized from 1,4-BAPON and various aromatic tetracarboxylic dianhydrides by the conventional two-stage procedure that included ring-opening polyaddition in a polar solvent such as DMAc, to give poly(amic acid)s, followed by thermal cyclodehydration to polyimides. Depending on the dianhydrides used, the poly(amic acid)s obtained had inherent viscosities of $0.81-1.33 \mathrm{dLg}^{-1}$. All the poly(amic acid)s could be solution cast and thermally converted into transparent, flexible, and tough polyimide films. These polyimides had glass transition temperatures between $247-281^{\circ} \mathrm{C}$. Thermogravimetric analyses established that these polymers were fairly stable up to $500^{\circ} \mathrm{C}$, and $10 \%$ weight loss temperatures were recorded in the range of $521-581^{\circ} \mathrm{C}$ in nitrogen and $517-575^{\circ} \mathrm{C}$ in air atmosphere. KEY WORDS 1,4-Bis(4-aminophenoxy)naphthalene / Polyimide /
\end{abstract}

Polyimides are high-performance polymers and widely used due to their excellent heat resistance and electrical insulating properties as well as mechanical characteristics in fields of electrical materials, adhesives, composite materials, fiber, and film materials. ${ }^{1,2}$

The most widespread route for the preparation of aromatic polyimides is the two-stage polyaddition and polycondensation of a dianhydride with a diamine in an aprotic solvent, such as $N, N$-dimethylacetamide (DMAc). A soluble poly(amic acid) is obtained as polyimide prepolymer in the first stage; cyclodehydration of this intermediate polymer, either by heat or chemical reagents, yields the polyimide.

Unless carefully designed polyimides are often insoluble and intractable in the fully imidized form, presenting serious processing difficulties. Therefore, preparation of soluble or thermoplastic polyimides has been a major research interest. Structural modifications such as the incorporation of flexible bridging linkages ${ }^{3-7}$ or meta-oriented or ortho-oriented phenylene rings ${ }^{8,9}$ into polymer backbone and introduction of bulky substituents ${ }^{10-14}$ along polymer skeleton have been used to enhance the solubility and to lower the phase transition temperatures. It has been generally recognized that aromatic ether linkings inserted in aromatic main chains provide significantly lower energy of internal rotation.

In general, such structural modifications lead to a lower glass transition temperatures $\left(T_{\mathrm{g}} \mathrm{s}\right)$ and crystalline melting temperatures $\left(T_{\mathrm{m}} \mathrm{s}\right)$, as well as significant improvements in solubility and other process characteristics of the polymers without greatly sacrificing thermal stability.

Several studies of the preparation of naphthalenecontaining polymers appear in the literature. ${ }^{15-20}$ The introduction of a naphthalene ring into the polymer backbone is expected to lead to decrease in linearity of polymer chain while maintaining comparable thermal stability in comparison with the benzene ring. Thus, the combination of aryl ether and naphthalene units into the polymer chain may be proposed for increasing the

\footnotetext{
† To whom correspondence should be addressed.
}

solubility of polymers without extreme loss of thermal stability. Some polyimides containing isomeric 1,6-, 1,7-, 2,3-, and 2,7-substituted bis(phenoxy)naphthalene units $^{21-25}$ are soluble in polar organic solvents and maintain good thermal stability, which suggests that bis(phenoxy)naphthalene-containing diamines would be potential monomers for preparation of soluble aromatic polyimides. Among all the bis(4-aminophenoxy)naphthalene isomers, 1,4-bis(4-aminophenoxy)naphthalene is the most difficult one which can be synthesized, because this monomer showed higher solubility than others and poor recrystallization in single solvent. The present article describes the synthesis of 1,4-bis(4-aminophenoxy)naphthalene as a new diamine monomer, and the preparation of polyimides by the polymerization of the diamine with various aromatic tetracarboxylic dianhydrides. Solubility, crystallinity, mechanical properties, and thermal properties of the polyimides were investigated.

\section{EXPERIMENTAL}

\section{Materials}

1,4-Dihydroxynaphthalene (from Fluka), $p$-fluoronitrobenzene (from Janssen), and $10 \%$ palladium on activated carbon $(\mathrm{Pd} / \mathrm{C}$ ) (from Fluka) were used as received. Reagent-grade aromatic tetracarboxylic dianhydrides such as pyromellitic dianhydride (PMDA, Ia; from TCI), 3,3',4,4'-biphenyltetracarboxylic dianhydride (BPDA, Ib; from Chriskev), 4,4'-oxydiph thalic anhydride (ODPA, Ic; from Chriskev), 3,3',4,4'-benzophenonetetracarboxylic dianhydride (BTDA, Id; from TCI), 4,4'sulfonyldiphthalic anhydride (SDPA, Ie; from New Japan Chemical Co.) were recrystallized from acetic anhydride before use. DMAc was purified by distillation under reduced pressure over calcium hydride and stored over $4 \AA$ molecular sieves.

\section{1,4-Bis(4-nitrophenoxy)naphthalene (1,4-BNPON)}

This compound was synthesized by reaction of 1,4dihydroxynaphthalene $(8 \mathrm{~g}, 0.05 \mathrm{~mol})$ and $p$-fluoronitro- 
benzene $(15.5 \mathrm{~g}, 0.11 \mathrm{~mol})$ in the presence of potassium carbonate $(13.8 \mathrm{~g}, 0.11 \mathrm{~mol})$ in DMAc $(50 \mathrm{~mL})$ at $120^{\circ} \mathrm{C}$ for $8 \mathrm{~h}$. The mixture was cooled and $300 \mathrm{~mL}$ of water added. The solid was filtered and washed with ethanol and hot water and the dry crude product was recrystallized from $100 \mathrm{~mL}$ of acetic acid to provide $14.6 \mathrm{~g} \mathrm{(73 \%}$ yield) of red crystal (mp $\left.169-171^{\circ} \mathrm{C}\right)$.

IR (KBr): $1342,1515 \mathrm{~cm}^{-1}\left(-\mathrm{NO}_{2}\right), 1235 \mathrm{~cm}^{-1}(\mathrm{C}-\mathrm{O})$. ${ }^{1} \mathrm{H}$ NMR $\left(\mathrm{DMSO}-d_{6}\right) \delta(\mathrm{ppm})=7.20(\mathrm{~d}, 4 \mathrm{H}, 3 \mathrm{~J}(\mathrm{~b}, \mathrm{c})=$ $\left.7.2 \mathrm{~Hz}, \mathrm{H}_{\mathrm{c}}\right), 7.26\left(\mathrm{~s}, 2 \mathrm{H}, \mathrm{H}_{\mathrm{e}}\right), 7.66(\mathrm{dd}, 3 \mathrm{~J}(\mathrm{~h}, \mathrm{i})=6.4$, $\left.4 \mathrm{~J}(\mathrm{~h}, \mathrm{i})=2.6, \mathrm{H}_{\mathrm{i}}\right), 7.92(\mathrm{dd}, 3 \mathrm{~J}(\mathrm{~h}, \mathrm{i})=6.4,4 \mathrm{~J}(\mathrm{~h}, \mathrm{i})=2.6$, $\left.\mathrm{H}_{\mathrm{h}}\right), 8.22\left(\mathrm{~d}, 4 \mathrm{H}, 3 \mathrm{~J}(\mathrm{~b}, \mathrm{c})=7.2 \mathrm{~Hz}, \mathrm{H}_{\mathrm{b}}\right),{ }^{13} \mathrm{C} \mathrm{NMR}$ $\left(\mathrm{DMSO}-d_{6}\right): \delta=116.2\left(\mathrm{C}_{\mathrm{e}}\right), 116.8\left(\mathrm{C}_{\mathrm{c}}\right), 122.1\left(\mathrm{C}_{\mathrm{h}}\right), 126.0$ $\left(\mathrm{C}_{\mathrm{b}}\right), 127.7\left(\mathrm{C}_{\mathrm{i}}\right), 128.1\left(\mathrm{C}_{\mathrm{g}}\right), 142.8\left(\mathrm{C}_{\mathrm{a}}\right), 147.8\left(\mathrm{C}_{\mathrm{f}}\right), 163.5$ $\left(\mathrm{C}_{\mathrm{d}}\right)$

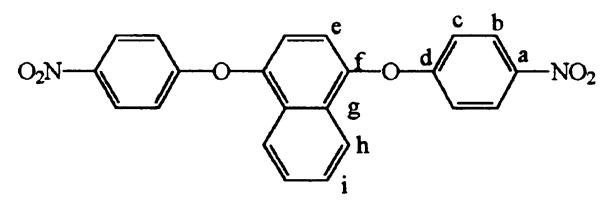

$$
\begin{array}{lllll}
\mathrm{C}_{22} \mathrm{H}_{14} \mathrm{~N}_{2} \mathrm{O}_{6}(402.36) & \text { Calcd. } & \mathrm{C} 65.67 & \mathrm{H} 3.48 & \text { N } 6.96 \\
& \text { Found } & \text { C } 65.70 & \text { H } 3.44 & \text { N } 6.84
\end{array}
$$

\section{1,4-Bis(4-aminophenoxy)naphthalene (1,4-BAPON)}

To a suspension of 1,4-BNPON $(10 \mathrm{~g}, 0.025 \mathrm{~mol})$ in ethanol $(100 \mathrm{~mL})$ was added $\mathrm{Pd} / \mathrm{C}(10 \%)(0.2 \mathrm{~g})$; hydrazine monohydrate $(6 \mathrm{~mL})$ was added dropwise to the stirred mixture at $85^{\circ} \mathrm{C}$ within $1 \mathrm{~h}$. The mixture was heated at $85^{\circ} \mathrm{C}$ for another $4 \mathrm{~h}$ and filtered to remove the $\mathrm{Pd} / \mathrm{C}$ and solvent was evaporated to yield the crude product. Yield: $8.04 \mathrm{~g}(95 \%)$; mp $113-115^{\circ} \mathrm{C}$ (pale red chip crystal was recrystallized from dichloromathane and hexane).

IR (KBr): $3437,3355 \mathrm{~cm}^{-1}(\mathrm{~N}-\mathrm{H}), 1236 \mathrm{~cm}^{-1}(\mathrm{C}-\mathrm{O})$. ${ }^{1} \mathrm{H}$ NMR (DMSO- $\left.d_{6}\right): \delta=4.92\left(\mathrm{~s}, 4 \mathrm{H}, \mathrm{NH}_{2}\right), 6.58(\mathrm{~d}$, $\left.4 \mathrm{H}, 3 \mathrm{~J}(\mathrm{~b}, \mathrm{c})=8.8 \mathrm{~Hz}, \mathrm{H}_{\mathrm{b}}\right), 6.66\left(\mathrm{~s}, 2 \mathrm{H}, \mathrm{H}_{\mathrm{e}}\right), 6.77(\mathrm{~d}, 4 \mathrm{H}$, $\left.3 \mathrm{~J}(\mathrm{~b}, \mathrm{c})=8.8 \mathrm{~Hz}, \mathrm{H}_{\mathrm{c}}\right), 7.56(\mathrm{dd}, 3 \mathrm{~J}(\mathrm{~h}, \mathrm{i})=6.4,4 \mathrm{~J}(\mathrm{~h}, \mathrm{i})=2.6$, $\left.\mathrm{H}_{\mathrm{i}}\right), 8.16\left(\mathrm{dd}, 3 \mathrm{~J}(\mathrm{~h}, \mathrm{i})=6.4,4 \mathrm{~J}(\mathrm{~h}, \mathrm{i})=2.6, \mathrm{H}_{\mathrm{h}}\right),{ }^{13} \mathrm{C} \mathrm{NMR}$ (DMSO- $\left.d_{6}\right): \delta=111.0\left(\mathrm{C}_{\mathrm{e}}\right), 114.9\left(\mathrm{C}_{\mathrm{b}}\right), 119.9\left(\mathrm{C}_{\mathrm{c}}\right), 121.8$ $\left(\mathrm{C}_{\mathrm{h}}\right), 126.5\left(\mathrm{C}_{\mathrm{i}}\right), 126.6\left(\mathrm{C}_{\mathrm{g}}\right), 145.1\left(\mathrm{C}_{\mathrm{a}}\right), 147.6\left(\mathrm{C}_{\mathrm{f}}\right), 149.1$ $\left(\mathrm{C}_{\mathrm{d}}\right)$

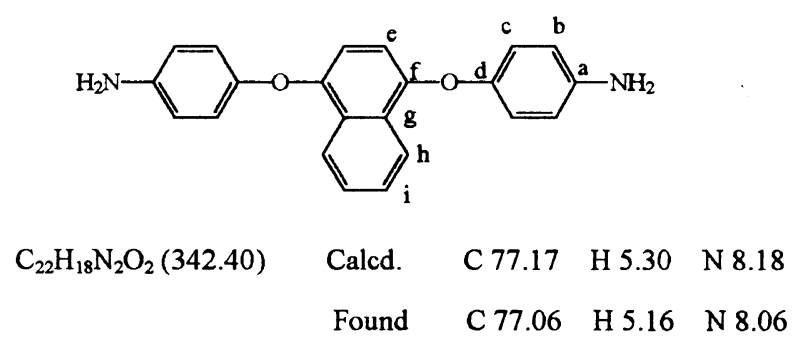

X-Ray single crystal data (atom numbers were the same with Figure 1):

Bond distances: C1-C1 1.407(5), C1-C2 1.414(4), C1-C4 1.408(4), C2-C3 1.351(5), C3-C3 1.392(7), C4 C5 1.341(5), C4-O 1.389(3), C5-C5 1.404(6), C6 C7 1.367(6), C6 C11 1.374(6), C6-O 1.404(4), C7-C8 1.371(6), C8-C9 1.373(5), C9-C10 1.375(6), C9-N 1.402(5), C10-C11 1.366(6).

Bond angles: $\mathrm{C} 1-\mathrm{C} 1-\mathrm{C} 2$ 118.3(3), C1-C1-C4 118.5(3), C2-C1-C4 123.2(3), C1-C2-C3 121.6(3), C2-C3-C3

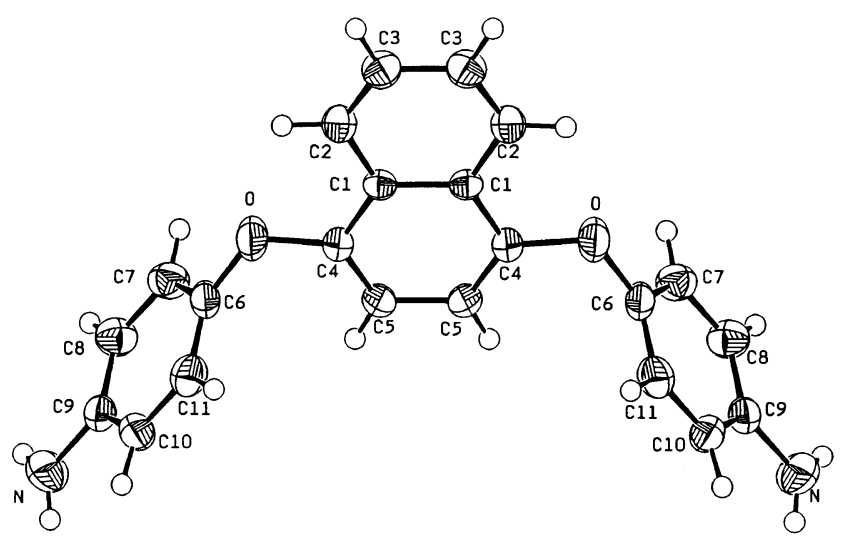

Figure 1. The structure of 1,4-BAPON.

120.1(3), C1-C4-C5 121.4(3), C1-C4-O 114.5(3), C5C4-O 124.1(3), C4-C4-C5 120.1(3), C7-C6-C11 119.5(4), C7-C6-O 119.9(3), C11-C6-O 120.3(4), C6C7-C8 120.5(4), C7-C8-C9 120.4(4), C8-C9-C10 118.7(3), C8-C9-N 121.3(4), C10-C9-N 120.0(3), C9C10-C11 121.0(4), C6-C11-C10 119.1(4), C4-O-C6 (2).

\section{Polymerization}

A typical example of polymerization is as follows. Into a solution of $0.4280 \mathrm{~g}(1.25 \mathrm{mmol})$ of $1,4-\mathrm{BAPON}$ in $6.75 \mathrm{~mL}$ of DMAc, $0.2725 \mathrm{~g}(1.25 \mathrm{mmol})$ PMDA was added portionwise within $30 \mathrm{~min}$. The reaction mixture kept stirred for another $2 \mathrm{~h}$. The inherent viscosity of the obtained poly(amic acid) (IIa) was $1.33 \mathrm{dL} \mathrm{g}^{-1}$. Chemical cyclization: $2 \mathrm{~mL}$ of acetic anhydride and $1 \mathrm{~mL}$ of pyridine were added to the poly(amic acid) solution and heated to $100^{\circ} \mathrm{C}$ for $1 \mathrm{~h}$ to obtain polyimide IIIa.

The inherent viscosity of the obtained polyimide (IIIa) was $0.92 \mathrm{dL} \mathrm{g}^{-1}$ as measured at a concentration of 0.5 $\mathrm{g} \mathrm{dL}^{-1}$ at $30^{\circ} \mathrm{C}$ in $\mathrm{H}_{2} \mathrm{SO}_{4}$. Thermal cyclization: poly(amic acid) solution was spread on a glass plate and baked at $80^{\circ} \mathrm{C}$ to remove the solvent. The semi-dried poly(amic acid) film was further dried and transformed into polyimide by heating at $120^{\circ} \mathrm{C}, 140^{\circ} \mathrm{C}, 160^{\circ} \mathrm{C}, 180^{\circ} \mathrm{C}, 220^{\circ} \mathrm{C}$, and $250^{\circ} \mathrm{C}$ each for $20 \mathrm{~min}$. The polyimide (IIIa) film was stripped from the glass substrate by soaking in hot water and dried at $100^{\circ} \mathrm{C}$ under vacuum. The other polyimides (IIIb-IIIe) were prepared by the same procedure from 1,4-BAPON and other tetracarboxylic dianhydrides (Ib--Ie).

\section{Measurements}

Melting points were measured in capillaries on a Yamato mp apparatus (Model MP-21) without correction. ${ }^{1} \mathrm{H}$ NMR and ${ }^{13} \mathrm{C}$ NMR spectra were recorded on a JEOL EX-400 NMR spectrometer operated at $30^{\circ} \mathrm{C}$ with tetramethylsilane (TMS) as the internal standard and DMSO- $d_{6}$ as solvent, respectively. IR spectra were recorded on a Jasco FT/IR-7000 Fourier-transform infrared spectrometer. Elemental analyses were run in a Perkin-Elmer model $2400 \mathrm{C}, \mathrm{H}, \mathrm{N}$ analyzer. X-Ray crystallographic data were collected on a CAD-4 diffractometer. The analyses were carried out on a BEC station 3500 computer using NRCC SDP software.

The inherent viscosites of all the poly(amic acid)s were measured at $0.5 \mathrm{~g} \mathrm{dL}^{-1}$ concentration with a CannonFenske viscometer thermostated at $30^{\circ} \mathrm{C}$. Thermogravi- 
metric analysis (TGA) was conducted with a Rigaku thermoflex TG 8110 coupled to a Rigaku TAS-100 thermal analysis station. Experiments were carried out on $10 \pm 2 \mathrm{mg}$ samples heated in flowing nitrogen or air $\left(50 \mathrm{~cm}^{-3} \mathrm{~min}^{-1}\right)$ at a heating rate of $20^{\circ} \mathrm{Cmin}^{-1}$. Differential scanning calorimetry (DSC) traces were performed on a Sinku-Riko DSC-7000 differential scanning calorimeter coupled to a TA 7000 thermal analyzer in flowing nitrogen $\left(30 \mathrm{~cm}^{3} \mathrm{~min}^{-1}\right)$ at a heating rate of $20^{\circ} \mathrm{C} \mathrm{min}^{-1}$. Wide-angle $\mathrm{X}$-ray diffraction patterns were obtained on a Rigaku Geiger D-Max IIIa X-ray diffractometer, using Ni-filtered $\mathrm{Cu}-K_{\alpha}$ radiation $(40 \mathrm{kV}$, $15 \mathrm{~mA}$ ) with film specimens of about $0.1 \mathrm{~mm}$ in thickness. The scanning rate was $2^{\circ} \mathrm{min}^{-1}$. An Instron universal test Model 1130 with a load cell of $5 \mathrm{~kg}$ was used to study stress-strain of the samples. Measurements were performed at room temperature with film specimens $(0.5 \mathrm{~cm}$ wide, $6 \mathrm{~cm}$ long, and $0.1 \mathrm{~mm}$ thick). The average of at least six individual determinations was used.

\section{RESULTS AND DISCUSSION}

\section{Monomer Synthesis}

By the route shown in Scheme 1, 1,4-BAPON was synthesized in two steps from 1,4-dihydroxynaphthalene and $p$-fluoronitrobenzene. In the presence of anhydrous $\mathrm{K}_{2} \mathrm{CO}_{3}$ in an amide-type solvent such as DMAc, dinitro compound 1,4-BNPON was formed by a nucleophilic fluorodisplacement reaction. After purification, 1,4-

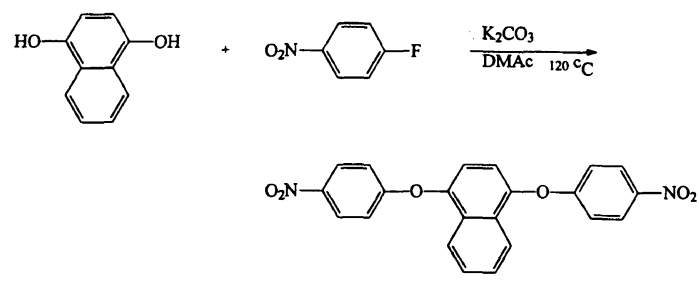

1,4-BNPON

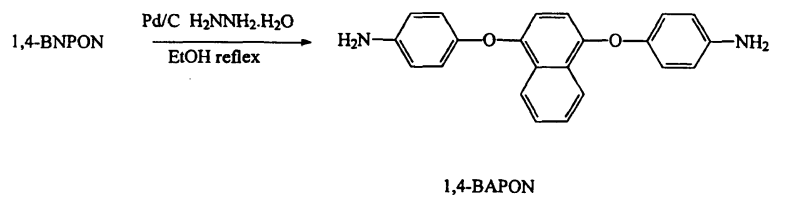

Scheme 1.
$\mathrm{BNPON}$ was reduced with hydrazine and $\mathrm{Pd} / \mathrm{C}$ in ethanol to the diamine 1,4-BAPON. Because of the purity of dinitro compound 1,4-BNPON is very important for the synthesis of the diamine 1,4-BAPON. To find the best conditions for the synthesis of 1,4-BNPON, different reaction conditions were used as shown in Table I. As shown in Run $1-3$, the reaction between the $p$-chloronitrobenzene and 1,4-dihydroxynaphthalene gave low yields $(47-52 \%)$, might be caused of the poor reactivity of $p$-chloronitrobenzene. When the higher reactivity reactant $p$-fluoronitrobenzene was used instead of $p$ chloronitrobenzene high yields $(76-84 \%)$ were obtained. Compared to previous studies ${ }^{21-24}$ the other dinitro isomers of 1,4-BNPON could be synthesized from $p$-chloronitrobenzene and dihydroxynaphthalene. This study shows the synthesis of $1,4-\mathrm{BNPON}$ to be more difficult than that of other isomers.

As shown in Table I, the best conditions for the synthesis of 1,4-BNPON were using 1,4-dihydroxynaphthalene to react with $p$-fluoronitrobenzene in the presence of 2 eq $\mathrm{K}_{2} \mathrm{CO}_{3}$ in DMAc at $120^{\circ} \mathrm{C}$. In the synthesis of the diamine monomer 1,4-BAPON purification was difficult. The other isomers of 1,4-BAPON could be easily recrystallized from ethanol, but 1,4-BAPON could be only recrystallized in the slow evaporation of $\mathrm{CH}_{2} \mathrm{Cl}_{2} / \mathrm{Hexane}$ cosolvent. The structures of $1,4-$ BAPON and intermediate dinitro compound 1,4BNPON were found by elemental analysis and IR, ${ }^{1} \mathrm{H}$ NMR, and ${ }^{13} \mathrm{C}$ NMR spectroscopy. As shown in experiment, the chemical shifts of $\mathrm{H}_{b}$ and $\mathrm{H}_{\mathrm{c}}$ changed from 8.22 and $7.20 \mathrm{ppm}$ in 1,4-BNPON to 6.58 and $6.66 \mathrm{ppm}$ in $1,4-\mathrm{BAPON}$. It was caused by that the strong electronwithdrawing $\mathrm{NO}_{2}$ groups were reduced to the strong electrodonating $\mathrm{NH}_{2}$ groups. The $\mathrm{NH}_{2}$ groups of 1,4-BAPON appear at $4.29 \mathrm{ppm}$ also show the reduction reaction has completed. The ${ }^{13} \mathrm{C}$ NMR spectra of 1,4-BNPON and 1,4-BAPON shown 9 peaks were also agree with the predict structure. The 2D ${ }^{1} \mathrm{H}-{ }^{13} \mathrm{C}$ COSY spectrum of $1,4-\mathrm{BAPON}$ with the aid of the 3rd order carbon spectrum assignment, the carbons $\mathrm{C}_{\mathrm{b}}, \mathrm{C}_{\mathrm{c}}, \mathrm{C}_{\mathrm{e}}, \mathrm{C}_{\mathrm{h}}$, and $\mathrm{C}_{\mathrm{i}}$ could be easily assigned from the correlation of the protons $\mathrm{H}_{b}, \mathrm{H}_{\mathrm{c}}, \mathrm{H}_{\mathrm{e}}, \mathrm{H}_{\mathrm{h}}$, and $\mathrm{H}_{\mathrm{i}}$.

The single crystal X-ray data of 1,4-BAPON are shown in EXPERIMENTAL. Refinement results in the structure (Figure 1) is agree with that deduced from the spectroscopic data.

Table I. Reaction conditions for the synthesis of 1,4-BAPON

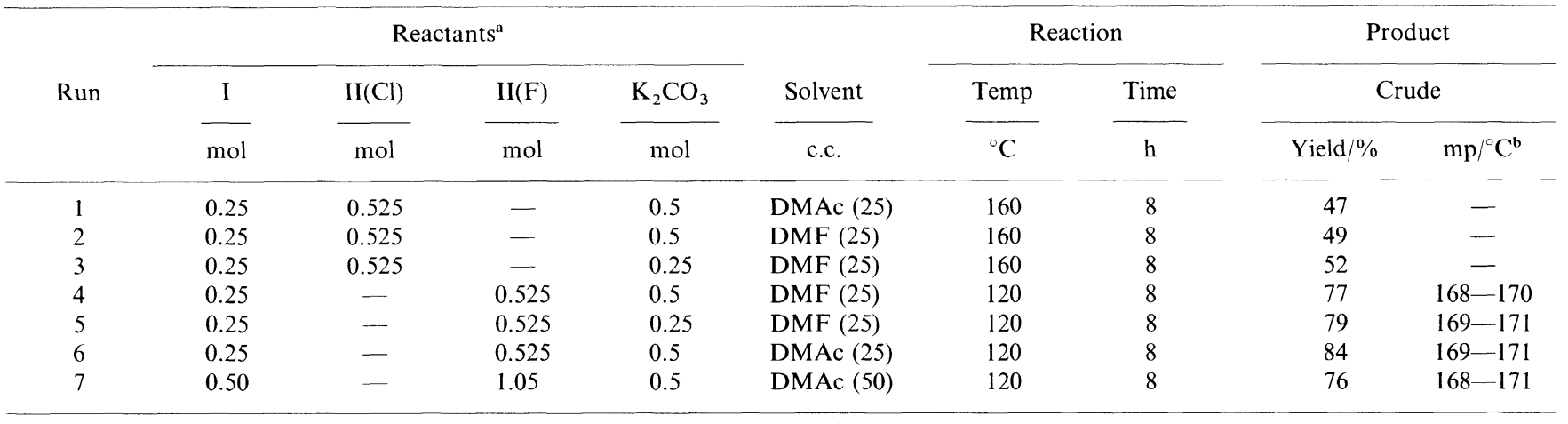

${ }^{a}$ Reactants: I, 1,4-dihydroxynaphthalene; II (Cl), p-chloronitrobenzene; II(F), p-fluoronitrobenzene. ${ }^{\mathrm{b}} \mathrm{Melting}$ point was measured after recrystallization. Cpd. 1, 2, 3, could not be recrystallized and their mp ranges were too large. 


\section{Polymer Synthesis}

New bis(phenoxy)naphthalene-containing aromatic polyimides IIIa - e were prepared from 1,4-BAPON and five commercially available dianhydrides by the conventional two-step procedure as shown in Scheme 2. In the preparation of poly(amic acid)s from aromatic diamines and dianhydrides in a polar solvent, monomer addition is important for polymerization. As described in the previous study, ${ }^{19}$ the diamine monomer was completely dissolved in the reaction solvent first. Adding solid dianhydride to the diamine solution produced higher

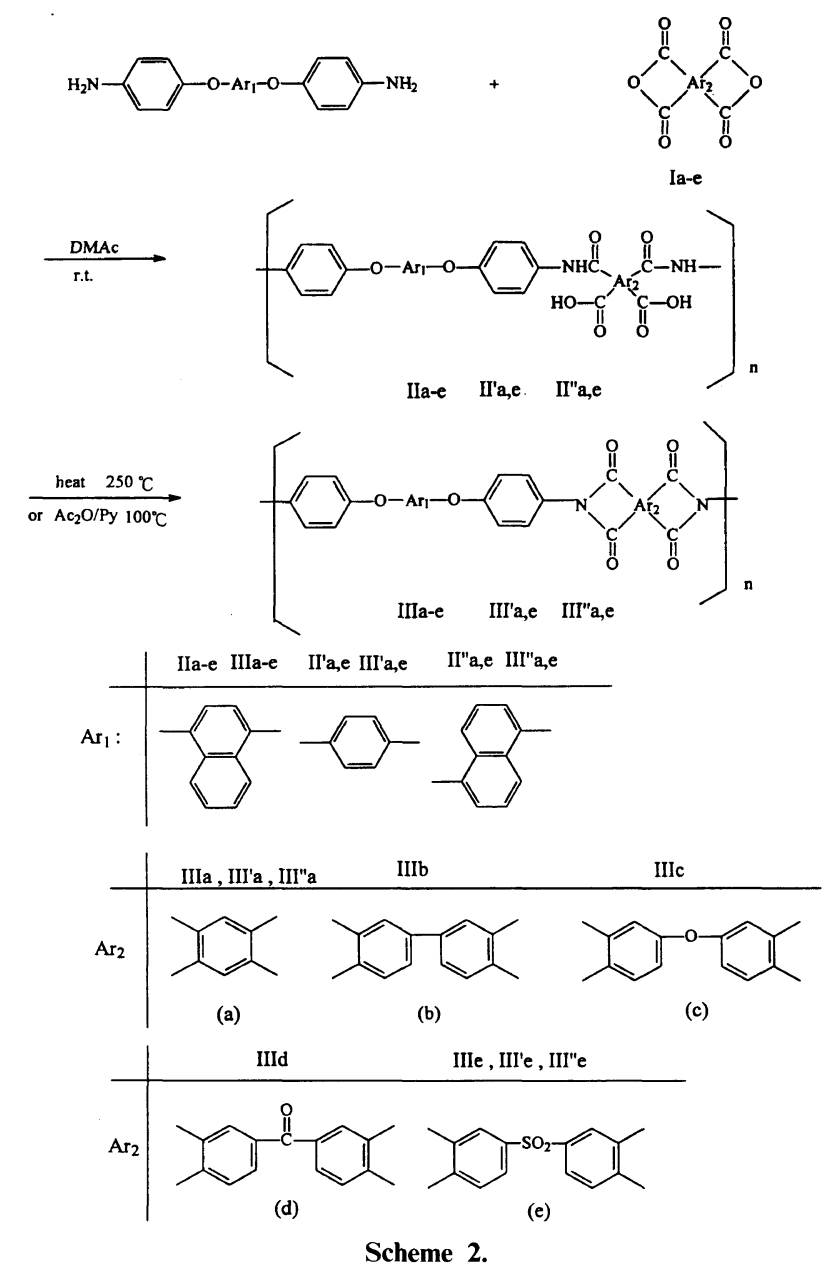

molecular weight poly(amic acid)s than the reverse addition mode. Thus, the poly(amic acid)s IIa-e were prepared by adding the solid dianhydride into the diamine solution. After the completely added of reactant, the reaction was carried out at a concentration of $10 \mathrm{wt} \%$. The inherent viscosities of all poly(amic acid)s, together with the corresponding polyimides, are summarized in Table II.

The inherent viscosities of these polymers in the amic acid stage were in the range of $0.81-1.32 \mathrm{dL} \mathrm{g}^{-1}$. For comparison, polyimides III'a and III'e containing 1,4bis(phenoxy)benzene unit were prepared from 1,4-bis(4aminophenoxy)benzene with PMDA and SDPA at viscosities of 1.15 and 0.76 respectively, on the amic acid stage.

Imidization was carried out by chemical cyclization or thermal cyclization. In the chemical cyclization treatment of poly(amic acid)s, acetic anhydride and pyridine were used. The inherent viscosities of these polyimides were in the range of $0.69-0.92 \mathrm{dL} \mathrm{g}^{-1}$ as measured in concentrated sulfuric acid.

In the thermal cyclization, films were cast from the poly(amic acid) solutions onto glass culture dishes, and imidization was achieved thermally by stepwise increase of temperature, with maximum imidization temperature of $250^{\circ} \mathrm{C}$ for $30 \mathrm{~min}$. The formation of polyimide was confirmed by IR spectroscopy. The IR spectra of the polyimides showed characteristic imide absorbances at 1780 and $1728 \mathrm{~cm}^{-1}$ (coupled carbonyls), and 1100 and $726 \mathrm{~cm}^{-1}$ (cyclic structures).

The element analysis results of these polyimides are shown in Table II and were generally in good agreement with predicted structures for hydrogen and nitrogen. The lower carbon analyses results than the calculated, was caused by the small coal reside left in the analysis. It was a phenomenon common to high temperature resistance polyimides. ${ }^{26,27}$

\section{Properties of Polymers}

The solubility (Table III) of the polyimides was examined in various solvents at room temperature with a concentration of $1 \%(\mathrm{w} / \mathrm{v})$. Although polyimide (IIIe) can be dissolved in $N$-methylpyrrolidone (NMP), other polyimides (IIIa-d) were all insoluble in all organic

Table II. Synthesis of polymers II and III from 1,4-BAPON and various aromatic tetracarboxylic dianhydrides

\begin{tabular}{|c|c|c|c|c|c|c|c|}
\hline \multirow{2}{*}{$\begin{array}{l}\text { Tetracarboxylic } \\
\text { dianhydride }\end{array}$} & \multicolumn{2}{|c|}{ Polyamic acid ${ }^{a}$} & \multirow{2}{*}{$\begin{array}{l}\text { Polyimide } \\
\text { code }\end{array}$} & \multirow{2}{*}{$\eta_{\mathrm{inh}} / \mathrm{dLg}^{-1 \mathrm{~d}}$} & \multicolumn{3}{|c|}{ Elemental analysis $/ \%^{\mathrm{e}}$} \\
\hline & Code & $\eta_{\mathrm{inh}} / \mathrm{dLg}^{-1 \mathrm{c}}$ & & & $\mathrm{C}$ & $\mathrm{H}$ & $\mathrm{N}$ \\
\hline Ia & IIa & 1.32 & IIIa & 0.92 & $\begin{array}{c}71.48 \\
(73.28)\end{array}$ & $\begin{array}{c}3.11 \\
(3.07)\end{array}$ & $\begin{array}{c}5.28 \\
(5.34)\end{array}$ \\
\hline Ib & IIb & 0.82 & IIIb & 0.71 & $\begin{array}{c}74.11 \\
(76.00)\end{array}$ & $\begin{array}{c}3.44 \\
(3.36)\end{array}$ & $\begin{array}{c}4.67 \\
(4.66)\end{array}$ \\
\hline Ic & IIc & 1.02 & IIIIc & 0.84 & $\begin{array}{l}72.53 \\
(74.02)\end{array}$ & $\begin{array}{l}3.27 \\
(3.27)\end{array}$ & $\begin{array}{c}4.45 \\
(4.54)\end{array}$ \\
\hline Id & IId & 0.81 & IIId & 0.69 & $\begin{array}{l}74.43 \\
(74.52)\end{array}$ & $\begin{array}{c}3.27 \\
(3.21)\end{array}$ & $\begin{array}{c}4.38 \\
(4.46)\end{array}$ \\
\hline Ie & IIe & 0.84 & IIIe & 0.73 & $\begin{array}{c}66.47 \\
(68.67)\end{array}$ & $\begin{array}{c}3.08 \\
(3.03)\end{array}$ & $\begin{array}{c}4.35 \\
(4.32)\end{array}$ \\
\hline
\end{tabular}

${ }^{a}$ Polymerization was carried out with equimolar quantities of $1,4-\mathrm{BAPON}$ and aromatic dianhydrides to obtain $10 \mathrm{wt} \%$ poly(amic acid) solution. ${ }^{\mathrm{b}}$ Obtained by chemical cyclization from the corresponding poly(amic acid)s. ${ }^{\mathrm{c}}$ Inherent viscosity measured in DMAc at a concentration of $0.5 \mathrm{~g} \mathrm{dL}^{-1}$ at $30^{\circ} \mathrm{C}^{d}{ }^{\mathrm{d}}$ Inherent viscosity measured in sulfuric acid at a concentration of $0.5 \mathrm{~g} \mathrm{dL}^{-1}$ at $30^{\circ} \mathrm{C}$. ${ }^{\mathrm{e}} \mathrm{Data}$ in parentheses are calculated values. 
Table III. Solubility and tensile properties of polyimides

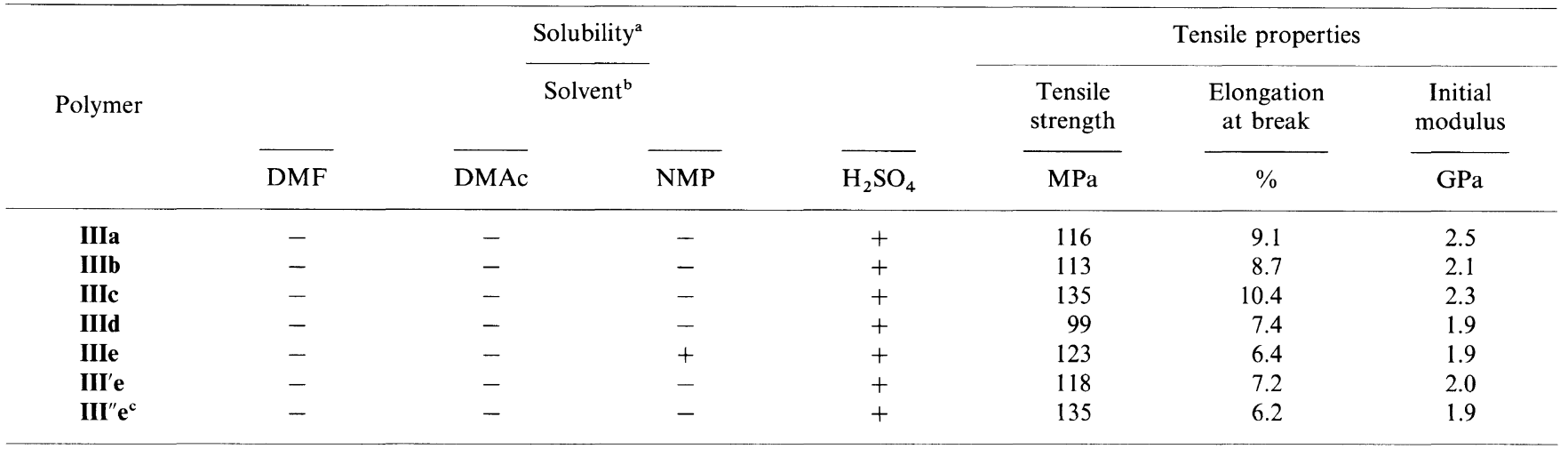

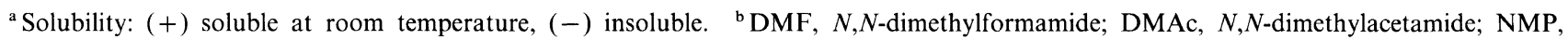
$N$-methyl-2-pyrrolidone. $\quad{ }^{c}$ The datas of III"e were obtained from ref 23.

Table IV. Thermal properties of polyimides

\begin{tabular}{|c|c|c|c|c|}
\hline \multirow{3}{*}{ Polymer } & \multicolumn{4}{|c|}{ TGA } \\
\hline & \multirow{2}{*}{$\frac{\mathrm{DSC}}{T_{\mathrm{g}}^{\mathrm{a}} /{ }^{\circ} \mathrm{C}}$} & \multicolumn{2}{|c|}{$\begin{array}{l}\text { Decomposition } \\
\text { temperature }{ }^{\mathrm{b}} /{ }^{\circ} \mathrm{C}\end{array}$} & \multirow{2}{*}{$\begin{array}{c}\text { wt } \% \text { Residue } \\
\text { at } 800^{\circ} \mathrm{C} \\
\text { in } \mathrm{N}_{2}\end{array}$} \\
\hline & & In air & In $\mathrm{N}_{2}$ & \\
\hline IIIa & - & 567 & 575 & 58.6 \\
\hline IIIb & 277 & 575 & 581 & 63.6 \\
\hline IIIc & 247 & 558 & 559 & 56.4 \\
\hline IIId & 260 & 527 & 530 & 64.6 \\
\hline IIIe & 281 & 517 & 521 & 51.7 \\
\hline III'a & - & 560 & 568 & 54.5 \\
\hline III" $^{\prime c}$ & - & 561 & 574 & 62.0 \\
\hline
\end{tabular}

${ }^{a}$ From the second heating DSC traces conducted at a heating of $20^{\circ} \mathrm{C} \mathrm{min}^{-1}$ in nitrogen. ${ }^{\mathrm{b}}$ Temperature at which a $10 \%$ weight loss was recorded by $\mathrm{TG}$ at a heating rate of $20^{\circ} \mathrm{Cmin}^{-1} .{ }^{\mathrm{c}}$ The data of III" a were obtained from ref 23 .

solvents. Compared to the similar polyimides III'e and III"e which were insoluble in all organic solvents, polyimide IIIe showed higher solubility than the other two. This implies that the incorporation of 1,4-bis(phenoxy)naphthalene units into the polyimide main chain improves solubility of polyimide. All the poly(amic acid)s could be solution cast and thermally converted into transparent, flexible, and tough polyimide films. Tensile properties are shown in Table III. These films have tensile strengths of $99-135 \mathrm{MPa}$, elongations at break of $6.4-10.4 \%$, and initial modul of $1.8-2.5 \mathrm{GPa}$. The film IIIa behaves as very rigid material and high initial modulus.

The crystallinity of polyimide films, prepared by thermal imidization, was evaluated by X-ray diffraction measurement with scattering angles $2 \theta$ from $5-40^{\circ}$. The patterns of all the polyimides were interpreted as due to amorphous nature.

The thermal behavior of the polymers was evaluated by DSC and TGA. Table IV summarizes the thermal properties of all the polyimides. Decomposition temperatures at which $10 \%$ weight loss $\left(T_{10}\right)$ observed were $521-581^{\circ} \mathrm{C}$ in nitrogen and $517-575^{\circ} \mathrm{C}$ in air, depending on the dianhydrides used. The char yields of polyimides at $800^{\circ} \mathrm{C}$ in nitrogen were between $52-65 \%$. The polyimide IIIb showed the highest thermal stability. Figure 2 shows the TG curves of polyimides IIIa and

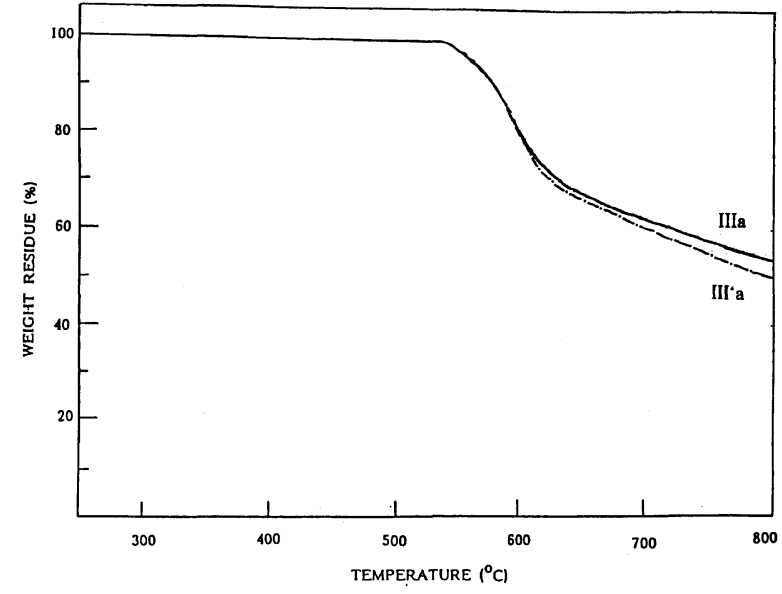

Figure 2. TGA curves of polyimides IIIa and III'a at a heating rate of $20^{\circ} \mathrm{C} \mathrm{min}^{-1}$ under nitrogen.

III'a with a heating rate of $20^{\circ} \mathrm{C} \mathrm{min}^{-1}$ under nitrogen. Both showed the high thermal stability below $500^{\circ} \mathrm{C}$. Compared to the thermal stability of IIIa and III'a, the former showed higher thermal stability than the latter. This was caused by the naphthalene containing structure underwent extensive carbonization upon non-oxidation degradation leaving higher char yield at $800^{\circ} \mathrm{C}$.

DSC measurements were conducted at a heating rate of $20^{\circ} \mathrm{C} \mathrm{min}^{-1}$. Quenching from the elevated temperatures $\left(c a .400^{\circ} \mathrm{C}\right)$ to room temperature in air gave more amorphous samples so that the $T_{\mathrm{g}} \mathrm{s}$ of the polyimides could be easily measured in the second heating traces of DSC. The $T_{\mathrm{g}} \mathrm{s}$ of the polyimides IIIa, III'a, and III"a derived from the rigid dianhydride PMDA could not be observed in the test range.

$T_{\mathrm{g}} \mathrm{s}$ of these polyimides were recorded in the range of $247-281^{\circ} \mathrm{C}$. The polyimide IIIc exhibited the lowest $T_{\mathrm{g}}$ of $247^{\circ} \mathrm{C}$. This is reasonable because its dianhydride moiety has a flexible ether linkage. The high $T_{\mathrm{g}}$ associated with polyimide IIIe derived from SDPA may be attributable to the presence of polar sulfonyl group which enhances intermolecular attraction between polymer molecules.

\section{CONCLUSION}

High-molecular-weight polyimides based on 1,4-bis(4- 
aminophenoxy)naphthalene and various aromatic tetracarboxylic dianhydrides were prepared as flexible and tough films. Almost all the polyimides showed an amorphous nature. The incorporation of 1,4-bis(phenoxy)naphthalene units into the polyimide backbone does not seem to lead to significant increase in solubility. However, these polyimides exhibited good properties such as high strength, excellent thermal stability, and large window between decomposition temperature and $T_{\mathrm{g}}$.

Acknowledgment. The authors are grateful to the National Science Council of the Republic of China for the support of this work (Grant NSC 85-2216-E-036008).

\section{REFERENCES}

1. K. L. Mittal, Ed., "Polyimides: Synthesis, Characterization, and Application," Vol. 1 \& 2, Plenum, New York, N.Y., 1984.

2. D. Wilson, H. D. Stenzenberger, and P. M. Hergenrother, Ed., "Polyimides," Blackie \& Son, Glasgow, 1990.

3. V. L. Bell, B. L. Stump, and H. Gager, J. Polym. Sci., Polym. Chem. Ed., 14, 2275 (1976)

4. T. Takekoshi, J. G. Wirth, D. R. Heath, J. E. Kochanocoski, J. S. Manello, and M. T. Webber, J. Polym. Sci., Polym. Chem. $E d$., 18, 3069 (1980).

5. W. A. Fled, B. Ramalingam, and F. W. Harria, J. Polym. Sci., Polym. Chem. Ed., 21, 319 (1983).

6. N. D. Ghatge, B. M. Shinde, and U. P. Mulik, J. Polym. Sci., Polym. Chem. Ed., 22, 3359 (1984)

7. Y. Imai, N. N. Malder, and M. Kakimoto, J. Polym. Sci., Part
A: Polym. Chem., 22, 2189 (1989).

8. A. K. St. Clair, T. L. St Clair, and E. N. Smith, Polym. Prepr., 17, 359 (1976)

9. H. J. Jeong, Y. Oishi, M. Kakimoto, and Y. Imai, J. Polym. Sci., Part A: Polym. Chem., 29, 39 (1991).

10. H. J. Jeong, M. Kakimoto, and Y. Imai, J. Polym. Sci., Part A: Polym. Chem., 29, 1691 (1991).

11. Y Oishi, M. Ishida, M. Kakimoto, Y. Imai, and T. Kurosaki, J. Polym. Sci., Part A: Polym. Chem., 30, 1027 (1992).

12. Y. Imai and M. Kakimoto, Polym. Plast. Technol. Eng., 28, 371 (1989).

13. M. Sato and M. Yokoyama, Eur. Polym. J., 15, 733 (1979).

14. M. Xie, Y. Oishi, M. Kakimoto, and Y. Imai, Polym. Prepr., Jpn., 37, 2966 (1988).

15. J. V. Crivello, J. Polym. Sci., Polym. Chem. Ed., 14, 159 (1976).

16. C. Chiriac and J. K. Stille, Macromolecules, 10, 710 (1977).

17. H. Escobar, F. R. Diaz, and R. S. Ramiraz, J. Polym. Sci., Polym. Chem. Ed., 14, 1167 (1976)

18. P. E. Cassidy and S. V. Docter, J. Polym. Sci., Polym. Chem. Ed., 18, 69 (1980).

19. M. Sato and M. Yokoyama, Eur. Polym. J., 15, 733 (1979).

20. M. Sato, Y. Tada, and M. Yokoyama, J. Polym. Sci., Polym. Chem. Ed., 19, 1037 (1981).

21. C. P. Yang and W. T. Chen, Macromolecules, 26, 4865 (1993).

22. C. P. Yang and W. T. Chen, Makromol. Chem., 194, 3061 (1993).

23. C. P. Yang and W. T. Chen, J. Polym. Sci., Part A: Polym. Chem. Ed., 31, 2799 (1993).

24. C. P. Yang, S. H. Hsiao, and C. C. Jang, J. Polym. Sci., Part A: Polym. Chem. Ed., 33, 1487 (1995).

25. C. P. Yang and J. H. Lin, J. Polym. Sci., Part A: Polym. Chem. Ed., 33, 2183 (1995).

26. C. P. Yang and J. H. Lin, J. Polym. Sci., Part A: Polym. Chem. Ed., 31, 2153 (1993).

27. S. H. Hsiao, C. P. Yang, and J. C. Fan, Makromol. Chem. Phys., 196, 3041 (1995) 